\title{
Medicine and the Pediatrician in Today's Poland
}

\author{
Maria Paluszny, M.D.*
}

I

N UNDERDEVELOPED COUNTRIES where diseases practically unknown in the United States are still prevalent, it is selfevident that the practice of medicine is affected by, and related to, the attitudes and culture and facilities of the environment. Furthermore, even in more sophisticated European countries these same factors can have a profound effect on the practice of medicine. In a recent visit to Poland, I decided to record my impressions of the status of medicine and particularly pediatrics. Naively, I intended to confine myself strictly to medicine. But, after discussions with several physicians (who preferred to remain anonymous), I found that medicine cannot be approached in a vacuum; its activities and

This article is based on personal experience during a visit to Poland in the summer of 1974 . For a detailed description of medicine and the health delivery system, the reader is referred to: Weinerman, E. Richard, Social Medicine in Eastern Europe, Cambridge, Harvard University Press, 1969.

* Associate Professor of Psychiatry, Universicy of Michigan Medical School; Program Director in Psychiatry, Institute for the Study of Mental Retardation and Related Disabilities, University of Michigan.

Correspondence to Maria Paluszny, M.D., Institute for the Study of Mental Retardation and Related Disabilities, University of Michigan, 130 S. First Street, Ann Arbor, Mich. 48108. practices reflect the culture and the economic and political system of the setting.

\section{Background and Setting}

Today's Poland can be described as a "young country" deeply rooted in tradition. Women, who became an important part of the work force during World War II, have maintained this importance and form a major segment of every professional and nonprofessional work group. That so many women are working outside the home, however, has not decreased the birth rate. Emphasis is still being placed on replacing the six million Poles killed during the Nazi occupation, and on rebuilding the destruction left by the war. Children and teenagers are everywhere. The rapid population growth is now declining, but this and the major destruction left by the war make adequate housing a most pressing problem. In the large cities, extended families live together, with space utilized as efficiently as possible. For example, few people have regular beds or bedrooms - most have hideaway beds so that the same rooms can be used for sleeping and as living rooms. Construction of apartments is a top priority and buildings in all stages of completion can be seen throughout 


\section{PEDIATRICS IN POLAND}

Acceptance into a medical school is strictly on the basis of academic excellence ... . and the grades achieved on the entrance examination. The old system of a bluecollar worker's son or daughter having an advantage over the child of an upper-class family is no longer applied.

the cities I visited. Perhaps the best example of rebuilding is Warsaw itself.

During the 63 days of the unsuccessful uprising in 1944, Warsaw was almost totally destroyed. Now virtually completely rebuilt, the city's streets are wider and its buildings have been modernized. As a place to live, Warsaw is essentially the same as it was in 1939, with only plaques on buildings - sites commemorating executions or particularly bloody battles of the war-as major reminders. The streets are busy, flled with pedestrians and motor vehicles. Passenger cars, once an unattainable luxury, are now common enough so that one can often be ensnarled in a traffic jam. During the summer, Warsaw is filled not only with the almost two million city dwellers, but with a constant influx of tourists as well. Travel among the East European countries is popular, and tourists from the west are no longer rare. The style of dress does not differentiate the tourist from the inhabitant, but there is one sure way of telling the two apart. The permanent resident always carries a shopping bag so as to be ready for quick purchases from the street's fruit and vegetable stands. Refrigeration is not yet widely used for food preservation, so daily marketing is the rule.

Despite the busy everyday life and forwardlooking orientation of the young Polish population, the past is not forgotten. Historic sites, old buildings, and even some trees over 200 years old are under government protection. Times before the war and the Nazi occupation are frequent topics of conversation. The strongly nationalistic anti-Nazi underground movement (AK), which was viewed with disfavor during the Stalin era, is now openly acknowledged as a heroic group and a TV program describing its exploits (Kolumbowie) is second in popularity only to Janusik - a Polish style Robin Hood.

Pride in Polish history and tradition does not exclude other influences. The west, particularly the USA, is admired and imitated. American life style may be criticized but American goods are deemed superior to home-produced articles. Generally, private enterprise is discouraged in Poland and the inadequacies in a capitalistic system are stressed, yet most people's greatest wish is to visit the USA. Nixon's resignation was expressed in the news media as disappointing, with the negative implications of Watergate not even mentioned.

Many of these aspects of Polish life influence pediatrics and the practice of medicine.

\section{Medical Studies}

Medical education begins immediately after high school and lasts six years. The Polish high school (or gymnasium) is thought to have a higher standard and stricter requirements for graduation than English or American schools. During the last years of high school, the student's curriculum is planned with the university in mind. Students who do not wish to be enrolled in university programs are steered to vocational, trade, or business schools before completing high school. For example, primary school teachers and nurses enter their respective studies before graduating from high school and thus do not have formal university training.

Acceptance into a medical school is strictly on the basis of academic excellence in high school and the grades achieved on the entrance examination. The old system of a blue-collar worker's son or daughter having an advantage over the child of an upperclass family is no longer applied. The entrance examination is judged to be more important; it stresses physics, chemistry, and biology. In addition, a foreign language is mandatory. Currently, medicine is a popular area of study and there are about four applicants for each available place. Women continue to outnumber male applicants and 60 per cent of the students in medical schools are female. 
The first years of medical studies are devoted primarily to basic sciences, with clinical work beginning only in the third year of medical school.

Currently, medicine is a popular area of study and there are about four applicants for each available place. Women continue to outnumber male applicants and 60 per cent of the students in medical schools are female.

After completing the six years, the student receives a degree of "Physician" and begins his official practice of medicine. In order to receive the title of "Doctor of Medicine," he rnust complete additional studies including the writing of a dissertation (this program resembles that of a Ph.D. candidate in the USA).

Every newly graduated physician is assigned by the county medical officer with the advice of a university consultant to serve in a hospital or clinic for two years. During this period of time, the young physician may also work on his doctorate and/or may begin to specialize in a branch of medicine.

Specialization is done in two stages. After working in a given area of medicine, the physician may take written and oral examinations to qualify as a first degree specialist. After another two or three years, if he continues to specialize, he may take additional examinations and qualify as a second degree specialist. Second degree specialists are acknowledged as leaders in their areas and frequently have appointments on a university faculty.

\section{The Physician's Life Style and Practice}

All physicians work in a regional hospital or clinic or have appointments in a university medical center. Many take care of private patients in addition to these appointments, but no physicians are totally in private practice. One physician explained why this does not occur. Apparently, if a physician sets aside a certain amount of time for private patients, the county officials estimate what his income should be for this period of time. $\mathrm{He}$ is then taxed according to this estimate and not according to his actual income. Thus, if he sets aside too much time for private practice, it will be financially unprofitable.

The average established physician makes about 5,000-6,000 zloty per month (approximately 100 dollars). This salary is adequate to live on, since rent is low, schooling (even university education) is essentially free, and vacations at minimal cost are usually available through one's place of employment. Food prices are generally deemed high, although to a tourist they seem low (the most expensive dinner in a top quality restaurant is less than one dollar). Luxuries such as an automobile are beyond the means of an average physician unless his wife has an income comparable to her husband's. Actually, this occurs quite frequently, as most women work and many of them have professional degrees.

\section{Typical Pediatric Practice}

Most physicians have more than one job. A typical pediatrician will spend some of his time in a clinic or hospital and then will see a few private patients. If he is on the faculty of a university, he has the added responsibilities of teaching and research, but he will have more access to private patients and his base salary will be higher than a physician without such an appointment.

The emphasis in pediatrics is on normal development and prevention. After the birth of her baby, each mother is issued a pamphlet that she has to follow, listing a schedule of vaccinations and normal checkups. Developmental problems represent the most frequent questions that mothers ask of the pediatrician, with concerns about poor appetite being the leading problem. In a country where the cost of food is generally considered high and where marketing is done daily, one can understand why the intake of food can readily become the focus for mother-child tensions.

Because the majority of mothers work, pediatricians are frequently involved in getting work releases for a mother who has a sick child. According to working conditions, all workers have four weeks vacation. Work- 


\section{PEDIATRICS IN POLAND}

ing mothers receive paid maternity leave; in addition, a working mother may have up to one month paid leave if she has a sick child.

Currently, pediatricians and others are concerned about the day care centers which take care of babies while mothers work. Some of these not only are responsible for babies during the working hours, but house children during the entire work week (Mon-

In order to receive the title of "Doctor of Medicine," he must complete additional studies including the writing of a dissertation.

day through Saturday morning). It is felt that most of these centers do not provide enough individual attention to babies, and that young children are frequently exposed to too many childhood diseases. The current tendency is to encourage private arrangements for taking care of young children, using all the members of an extended family as babysitters.

Another major concern in the medical health field lies in the increasing divorce rate. Traditionally, Poland, a Catholic country, has had few divorces, but lately the rate has been soaring upwards. Lack of adequate housing is cited as a major reason for this trend. Physicians sometimes endeavor to help a young couple obtain separate living quarters for mental health reasons or to prevent a divorce. In such cases, the pediatrician will usually initiate an introduction to a mental health clinic rather than becoming directly involved. Referral to mental health clinics (which are usually staffed by psychologists) is a common practice among pediatricians and even minor problems such as enuresis are frequently transferred for management.

From a personal standpoint, many pediatricians and also other physicians feel that their work hours are too long and the financial rewards too small. From a health service delivery aspect, they feel that there are still shortages in staff and inadequacies in facilities in certain parts of the country. Generally though, they are optimistic about the future, since many advances have already been made in Poland. They feel confident that as the socioeconomic and political situations continue to improve, so will their life styles and the practice of medicine.
Scarlet fever, rubella, and measles are first, second, and third. Fourth, if it exists, is Filatow-Dukes's disease; fifth is erythema infectiosum; and sixth is exanthum subitum.

Erythema infectiosum is also known in America as "slapped cheek disease." The rash is most prominent on the cheeks, where it first appears as bright macules which finally run into one another; it does not rise above the malar bones nor run across the mouth. The rash later comes out on the limbs and, very sparsely, on the trunk, but is always less bright there; it has been described as lace-like, reticular, annular, or serpentine, but in truth it is rather nondescript. It persists for a week or ten days.

Other symptoms are slight and vague-malaise, a few aches, or headache. There are no after-effects. It occurs in sharp outbreaks, often in school children. The main age incidence is in the two-14-yearold age group. The incubation period is four to 14 days. It seems to spread by droplet infection, and is probably a virus disease.-From Fourth, Fifth, and Sixth in the British Medical Journal, November 23, 1974.
The "Fifth Disease" 